\title{
Contribution of Social Service in the Health Care of Elderly People in Palliative Care in Contemporary Brazil
}

\author{
Jackson Santos dos Reis ${ }^{1}$, Alan Silva das Virgens ${ }^{2}$, Daniel Vicentini de Oliveira ${ }^{3}$ and Mateus Dias Antunes ${ }^{4 *}$ \\ ${ }^{1}$ Master in Gerontology, Unyleya University-UNYLEYA, Brazil
}

${ }^{2}$ Graduate Program in Languages, Federal University of Sergipe-UFS, Brazil

${ }^{3}$ Doctor in Gerontology, Campinas State University-UNICAMP, Brazil

${ }^{4}$ Master in Health Promotion, University Center of Maringá-UNICESUMAR, Brazil

*Corresponding author: Mateus Dias Antunes, Master in Health Promotion, University Center of Maringá, Brazil

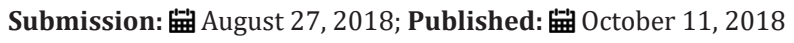

\begin{abstract}
Objective: The aim of this article is to analyze and delimit the correlation between the population growth of the Elderly people in Brazil and its relation with the Palliative Care and the instruments used by the Social Service to intervene in this social reality, analyzing on the approaches of the policies of specific attention.

Methods: This is a qualitative research of literature review using publications made available in databases, published as primary sources such as books, articles, and theses.

Results: In the analysis it was observed the absence of scientific theoretical articulation to support new models of execution and intervention for the Social Service and Palliative Care.

Conclusion: This article evidences the absence of a theoretical framework to delimit the intervention of the Social Service in Palliative Care, relegating the professional category to the role of mere performer, contrary to its constitutive genesis.
\end{abstract}

\section{Introduction}

The natural process of illness and death of the human being has always been in the center of the most diverse areas of professional activity, as something painful and difficult to be treated naturally. Palliative Care aims to articulate knowledge and techniques to deal with the termination process of human lives [1]. To be considered an elderly or young population [2:21] states that "A country is considered young when less than $7 \%$ of its population is 65 years old: when $14 \%$ have reached this age it is considered to be aged." The population aging observed in our country is "a reflection of the increase in past fertility, which reflects a trend in the future that will generate a larger contingent of elderly people in Brazil", Freitas [1:58] adds. Still focusing on aging, the contingent of the Elderly in Brazil doubled from 1940 to 2010 "Given the continuous reduction of mortality, especially in the advanced ages, this contingent is expected to reach a total of 13,7 million in 2040 , which means $6.7 \%$ of the total population and $24.6 \%$ of the elderly population "[1:59]. We are experiencing an intense and rapid process of population growth, which is important in sustaining all social policies, and is also an adjunct to the process of caring for the elderly, whether fundamental or specialized. The United Nations ratified the growth of the world population in 2050, the population of the Elderly in the World will exceed $20 \%$ of the world population of $30 \%$ of the Brazilian population. Contrasting the need to expand the assistance network to the elderly and social plans, for this social segment.

Aging in Brazil brought distinct characteristics, such as the need to expand targeted policies, such as investment in Health Programs, and, in contrast to that dynamics, in 2006 was published in the National Policy on Senior Citizens [2], The issues prevention, promotion, care and rehabilitation within the Unified Health System [3]. Health is a constitutional right, as well as an advance to the elderly, and this is anchored by the articles of the Federal Constitution of 1988, art. 196 and art. 230 of 1988, also by the Statute of the Elderly [2]. Obviously, the natural and constant process of illness for the elderly is of fundamental relevance, in their condition and social reality, considering the various aspects that interfere in their autonomy and socialization, either in their family group or in their social interrelationship at all. The formulation and adequacy of public policies to this reality should be based on the democratization of the theoretical discussion based on "equity, effectiveness and social efficiency, that is, the integral coverage and universali- 
ty of access of the population to the services" [1:1614]. The palliative patients who recurrently have caused a dislocation in their specificities within the particularities of Brazil, once that patient in palliative action has as a presupposition a chronic disease of slow or rapid degeneration that does not have treatment in the curative medical model (extinction of the disease) [1]. In this context, delimiting the contributions between Palliative Care and Social Service in the attention to the Elderly, establishing a scientific parallel is a reflection of professional praxis. Expanding the studies on palliative care is to reject consolidated data, which give a broad proportion of the need for long-term policies for the elderly, allowing a better understanding of the praxis of the Social Work in Palliative Care, as a pioneering scientific analysis that will guide the understanding of the social and academic dynamics in the theme Health of the Elderly.

The article aims to delimit through a literature review the correlation between the population growth of the Elderly in Brazil and its relationship with the Palliative Care and the instruments used by the Social Work to intervene in this social reality, focusing on Palliative Care on Elderly in Brazil, also discussing the approaches of the policies of specific attention. This is, therefore, a scientific work that will enable the updating of Social Work professionals about the specificities of the work with the Elderly and the aging process in Brazil, thus [4] the literature review is determinant in the construction of this research, becoming an inseparable instrument in the construction of knowledge and filling gaps not yet explored in the topics addressed. Using thesis and reference books for the subject as a database, as well as articles indexed in national scientific journals.

\section{Discussion}

The Elderly person in Brazil, by convention of the Statute of the Elderly in the Law no. 10741/2003 in Article 1 defines that people who are 60 (sixty) years old or more are considered as Elderly. Aging in Brazil has been a continuous process linked to the fall in fertility as in mortality, which has generated a large increase in the population over 60 years old. The aging process around the world has brought numerous difficulties and challenges to social and economic policies, due to the socio-demographic growth of an age group that requires the viability of specific health policies, within the prevention, promotion and rehabilitation, which has made this biological process of analysis and discussion inside the society. According to the Statute of the Elderly, the family and the State are the agents of protection and maintenance of the elderly's well being, under these conditions Brazil formalized the social organization in this segment, since the population growth in the Elderly segment is observed since 1940, and as a result of this effect the contingent of elderly people reaches $8.6 \%$ of the total population in Brazil in the year 2000 [5].

According to the Brazilian Institute of Geography and Statistics [6] in Brazil, the elderly reached a life expectancy of 74.1 years old in 2011, exceeding in this way the percentage of $4.1 \%$ in 1940 to $12 \%$ in 2011. In 2020, $14 \%$ of the Brazilian population is predicted to be Elderly. This growth is due to the advancement of medicine and the drop in the birth rate, so that life expectancy has been generated, which has generated a large contingent, causing some social disturbances, thus requiring concrete action in the health area to guarantee the minimum survival and recovery of its autonomy. Aging in Brazil has been characterized by disparities, in a way that the social policies of the elderly segment require a reflection and paradigms' change, necessarily relegating to the Public Power, alternatives to this new social scenario. Health is a constitutional right, as well as assistance to the elderly, and is anchored by articles of the Federal Constitution of 1988 Art. 196 and Art. 230 of 1988 also by the Statute of the Elderly.

Thus, in this perspective, we can observe the minimum guarantee in Article 196 of the Constitution "Health is the right of everyone and the duty of the State, guaranteeing, through social policies ... reduction of disease risk ... actions and services to their promotion, protection and recovery" [7]. The constitution guarantees the following guidelines: "universality, equity, uniformity, and equivalence, irreducibility of values of benefits, democratic, decentralized and participatory management" [8:238] being a guarantee and duty of the State. For the recurrent inquiry in the Law 8.080/90 and the regulation of the Organic Law of Health - OLH when it is altered in the text of Law 8.142/90, the Unified Health System result of the historical struggles for the democratization of health, has as principles the municipalization and the model of individual assistance, Sanitary and Epidemiological Surveillance [8]. With such a constitutional presence, the process of redemocratization of health and welfare rights is reflected, a long and intrinsic process in class struggles in contrast to the economic model in force in the period. It is still protected by the Statute of the Elderly, Geriatrics and Gerontology in Article 15 of the Statute of the Elderly. Obviously, the natural and constant process of illness for the elderly is of fundamental relevance, in their condition and social reality, considering the various aspects that interfere in their autonomy and socialization, either in their family group or in their social interrelationship at all.

The formulation and adaptation of public policies to reality should be based on the democratization of the theoretical discussion based on "... equity, effectiveness and social efficiency, that is, the integral coverage and universality of the population's access to services" [1:1614]. In the Constitution, the Unified Health System was implemented by Law 8.080 of 1990 . The Article 198 establishes and determines its functionality and particularities, which we can measure to the policies focused on care for the elderly, thus: "the actions of public health services integrate a regionalized and hierarchical network and constitute a unique, organized system [9]. The Article 3rd of the National Policy on the Elderly makes it clear the duties of entities and institutions involved in the care and maintenance of the elderly's life, guaranteeing dignity and the right of life of the elderly. Regarding to the rights of the elderly, several public policies have been promulgated for the protection and development of affirmative action through various national struggles and debates [10]. 
It can be codified that the population growth propitiated the demand for the development and discussion of actions with the elderly, the decoupling between the economic and social axes in the implementation of social policies, linked to the capitalist project that makes the policies of basic attention and specialized in old age precarious, impacting directly on the policies of Social Assistance and Social Security, with the need to extend social control and compliance with social policies for the elderly, Freitas [1:1622]. In the field of health emerges the insertion of the Social Worker in the at tention of the elderly at all levels [11]. The Statute of the Elderly is recognized as a milestone in the defense and guideline of the Rights of the Elderly, and it was instituted by Law 10.741/93, consisting of 118 Articles that deal with treating and defining the role of the family, State and society in maintaining and guaranteeing the well-being of the elderly.

Themes such as health, education, culture, food, sports, leisure, work, housing, citizenship, all in articulation to subsidize the guarantee of the dignity of the Elderly are determinants in the text. Still regarding to health, the guidelines for prevention, promotion, protection and recovery of health are guided by Art. 15, which is guaranteed by the articulation with the Unified Health System UHS (SUS BRASIL) [9]. According to the data from the Institute of Applied Economic Research [12], the elderly population is characterized by heterogeneity, being necessary the differentiated study of two age groups such as: 60 to 79 and over 80 years old, still on the subject the organ treats that the gender condition is intrinsic in the tangent to the elderly segment, being essential to observe that about $55 \%$ of the population over 60 years old are women. Camarano [5] emphasizes that the world of the elderly constitutes the world of women, asserting that in rural areas the concentration of men is significant and in the urban areas the concentration of women, this is due to the isolation in the urban area. Lloyd-Sherlock [5] points out that this feminization of the Brazilian elderly is caused by the probability of being widows, which still is characteristic of the physical fragility in this group.

The distribution by color or race is characterized by the following data: "8.8 million white elderly, followed by 1 million blacks and 4.4 million were brown, respectively, $60.7 \%, 7,0 \%$ and $30.7 \%$ of the elderly population "[5:30], which characterizes less than $1.2 \%$ of yellow and indigenous people, according to the study of the Institute of Applied Research - IPEA, which states that in 2000 a large part of the elderly population was in the Northeast and Southeast regions at a rate of $70.8 \%$, mainly in urban areas. In terms of scholarity, the increase was about $146 \%$ among women, and $59 \%$ among men, thus demonstrating an increase in scholarity among the Brazilian elderly, also due to the fact that public initiatives with literacy and University of the Third Age. In the health issue, there is a remarkable change in the epidemiological pattern, which has significant implications in the life and health conditions of the elderly, reflected by the mortality rate, plus a concise analysis of health policy initiatives in the segment for people over 60 years old. The fall in mortality reflected directly in the survival rate expressed in the male life expectancy from 58.5 to 67.5 years old, and female mortality of 76 years old, in a reference from 1980 to 2000 [13]. In contrast to the challenge of the quality of life of the Elderly in Brazil, [14] the State has not made great advances in the care and maintenance of life for the over 60 years starting from the analysis of social security and health and welfare policies.

A process of fragmentation of actions of interaction and guarantee of rights still glimpsing the advances in the norms of guarantees, but with the regressions in the neoliberal economic policy that tendentiously refers to the Elderly category as a public that does not produce capital being relegated the social minimum. The economic losses and epidemiological transition, reflecting health, led in 2006 to the publication of the National Policy on the Elderly [3], which seeks to promote and rehabilitate articulation through the Unified Health System, which is the largest instrument of health promotion of the Elderly in Brazil. Studies and discussions about palliative care dated from 1980, initially in Rio Grande do Sul and Rio de Janeiro by the National Cancer Institute. In 1997 the Brazilian Association of Palliative Care was created so that the philosophy of the Hospice was operationalized, in compliance with the peculiarities of the country though. In 1998 emerged the first service dedicated to palliative care at the National Cancer Institute in Vila Isabel [1].

The ministerial Order $\mathrm{n}$ - 3.535/GM of September 2nd, 1988 determines some peculiarities about palliative care in Brazil, which has the peculiarity of belonging to specialized health care. In the definition of the Registration Rules of specialized centers, it determines in Item 1.3 "Palliative Care - which includes outpatient care, hospital and home care by a multidisciplinary team to control pain and other symptoms presented by patients refractory to previously established treatments". In the characterization in Item 3.4.7 among other things defines the presence of the Social Worker in the Palliative Care team. It can be noticed that Brazilian legislation has sought to help the context and historical monitoring of defense, and progress in methodological terms, international palliative care. Faced with so many discussions about the implantation of techniques in palliative care and its guidelines, the Brazilian Association of Palliative Care emerges in 1997 in the cty of São Paulo to articulate the knowledge and enable scientific discussions that reinforce the scope of development in the care of patients in Terminality [15].

Brazil in consonance with what happens in a developed country has precise theoretical instruments that define and normalize the mechanisms of control and determinants to the detriment of the termination process. It can be seen an articulation of ideas in the care, and care with the thematic of patients in Palliative Care, as far as it concernes the health policy of the country. In the construction of the Social Service in Health, we can see that there are several ways to go, and difficulties to overcome, which is still bound to clinical practice, is thus historically consolidated, that will have to be broken, still confirming that the occupational Health and legitimate field of action for proposal of intervention routing and theoretical, methodological practice of Social Work. The Public Health System will certainly encounter difficulties, obstacles, in the agents that put it into functionality, because these are compromised about the direction and progress to be achieved [16]. In Resolution No. 
$383 / 99$ of the Federal Council of Social Service, and in the resolution of the Ministry of Health no 218 of 6/3/1997, the condition of the Social Worker as a health professional was ratified, in line with the 10th National Health Conference. The interdisciplinarity allows the construction of a broad network of protection, in the most diverse situations that professionals face in palliative care, these multidisciplinary acts aim to control situations such as pain control, psychological, social and coping with the proximity of death [17] It justifies tha for a better understanding of the control of diseases and their symptoms, it is necessary to observe the need for an interrelationship between psychological, socioeconomic and environmental factors.

Carrying out the analysis of the socioeconomic and family conditions of the patient together with an interdisciplinary team, propose a coordinated action that is more appropriate to the reality experienced from the patient to their respective family or family nucleus that reminds us of the Guidel of Palliative Care [18] . The reception and qualified hearing, to understand and systematize this social context of the patient has an aggravating factor regarding the family in question [19]. It is ensured that the patient has his or her needs aimed, that someone who is reliable for him or her is constituted as a legal representative, ensure that he or she is aware of the clinical status, the kind of therapy and the diagnosis, constitutes effective actions of the Social Worker by expanding and systematizing the network of patient support in terminality, enabling staff and relatives, the needed support. The information and communication about the clinical conditions of the patients is the physician's task, but the Social Worker in the multidisciplinary team should clarify to all the people who are involved about the legally based situations, besides ensuring that the results are understood by all involved in the matter. In this way, it can be seen that the social service is interventor in which is related to social relations and interdisciplinary articulations for the real viabilization of patients' rights in palliative care.

\section{Conclusion}

The normalization of Palliative Care was deeply linked to the concept of a dignified and respectful death, in this opportunity it was constituted by Cecily Saunders who had studied to be a Social Worker. The Palliative Care emerged in the World as an alternative, the process of death, due to chronic diseases, being used to meet the demands of a wide care that could be used with wide parameters to accommodate families, patients and multidisciplinary team. The Social Service is constituted as a profession linked to the struggle of the working class to overcome the social issues emerging from the social precarization caused by the neoliberal system. As a reflection of this movement, we realize that social policies and guidelines for the protection of the elderly, such as the Elderly Statute, National Elderly Policy and articulations in the implementation of the National Humanization Policy, have suffered setbacks, which implies in the lack of articulation and viability of rights policies. Palliative care in Brazil has made great strides in its discussions, in order to strengthen and develop ever more insurance parameters that can thus rescue and guarantee the right to the patient in a state of ter- mination with respect to the human person and his or her dignity. We can highlight the contribution of the Brazilian Society of Geriatrics and Gerontology, as well as the National Academy of Palliative Care, which promotes attention to the elderly in a termination process, due to the great population growth, which becomes a major challenge to State in the development and strengthening of policies focused on the elderly.

Once again, it is evident that Palliative Care for the Elderly is an important practice, in the perspective that Brazil is aging, but without quality in health, the basic health care of the Elderly is not being implemented yet as it is determined by the legal instruments at the national level, in this sense with the commitment of chronic diseases (hypertension, diabetes, etc ...), other chronic degenerative pathologies (neoplasms), it is ratified the need for humanized attention in a process of fragility in the advent of death or termination, it is worth mentioning that Palliative Care extends the concept of care and health care, providing care and multidisciplinary assistance to the family, supporting and rectifying a health policy that is primary in the Unified Health System.

The Social Worker, in this course of care and intervention in Palliative Care, develops an orientation led to the family, articulation as a multidisciplinary and interdisciplinary team, and the possibility of guaranteeing rights, since the Letter of Human Rights for the Federal Constitution of 1988 and its rectifications and normative decrees. Once this is the professional that has broad knowledge in general education, focused on applied human science, a subject of great value in attention in the Palliative care can be constituted. Using social anamnesis, interview, social and funeral orientation, institutional articulation, social referral among many other theoretical and methodological tools, the Social Worker is fully instrumented to face the most diverse possibilities that may occur in Palliative Care for the Elderly. Its action is supported by the Federal Constitution of Brazil, in the Statute of the Elderly, in the National Policy on Elderly Citizens, in the Ethical-Political Project of Social Work, in the Code of Professional Ethics, and in the Parameters of Social Work in Health, these group of laws guide and determine the attributions and possibilities of the professional in health policy. We can conclude that the Social Worker is a fundamental part of the constitution of Palliative Care for the Elderly in its most diverse specificities and particularities. In this article it is evident the absence of a theoretical framework to delimit the intervention of the Social Work in Palliative Care, relegating the professional category to the role of mere performer, which is the contrary of its constitutive genesis.

\section{Interest Conflicts}

The authors confirm not to have interest conflicts in which is concerned to this present study.

\section{References}

1. Freitas Elizabete V (2012) Geriatrics and gerontology treaty. ( $3^{\text {rd }}$ edn), Guanabara Koogan, Brazil, 59: 1614-1622.

2. Ministry of Social Development and Fight against Hunger-Brazil (2010) National policy of the elderly. (1 $1^{\text {st }}$ edn), Reprint. Brasília, Brazil. 
3. Duarte, Elisabeth C, Barreto, Sandhi M (2012) Demographic and epidemiological transition: Epidemiology and Health Services revisits and updates the theme. Epidemiol Serv Health Brasília 21(4): 529-532.

4. Bento A (2012) How to make a literature review: Theoretical and practical considerations. Revista JA (Academic Association of the University of Madeira), Portugal, 65: 42-44.

5. Ana Amélia C (2004) The new brazilian elders: Beyond the 60? /IPEA, Brazil.

6. Brazilian Institute of Geography and Statistics-IBGE (2011) Synopsis of the demographic sensor of 2010, Brazil.

7. From Brazil, the Federal Senate (1988) Constitution of the federative republic of Brazil. Federal Senate, Graphic Center, Brasília, Brazil.

8. Vasconcelos Ana M (2011) The practice of social work: Daily life, training and alternatives in the health area. ( $3^{\text {rd }}$ edn), Cortez, São Paulo, Brazil, p.238.

9. Law No. 8080/90, of September 19, 1990. DF. 1990, Brazil.

10. Ministry of Health (2007) Charter of the rights of health users/Ministry of Health-( $2^{\text {nd }}$ edn $)$. Ministry of Health, Brazil.

11. Maria Inês B (2012) Health and social service, (organizers)-( $5^{\text {th }}$ edn), São Paulo, Cortez, UERJ, Brazil.
12. Alcântara AO, Amélia Camarano A, Cristina Giacomin K (2016) National politics of the elderly: Old and new issues, Ipea, Brazil

13. Lima C, Fernanda M, VERAS, Renato (2003) Public health and aging. Cad Public Health 19(3): 700-701.

14. Chaimowcz, Flávio (2013) Health of the elderly ( $2^{\text {nd }}$ edn), Nescon Ufmg, Brazil, pp. 21-58.

15. Melo. Ana Carolina Cavalcanti de (2008) Palliative Care in Brazil. Brazilian Journal of Palliative Care, São Paulo, Brazil, 101(1).

16. Mioto, Regina Célia T, Nogueira, Vera Maria R (2006) Systematization, planning and evaluation of actions of social workers in the field of health. In: Mota AE, Bravo MIS, Uchôa R, Nogueira V, Marsiglia R, et al. (Eds.), Social Work and Health: Training and professional work. Creative Commons License.

17. Palliative Care/Institutional Coordination of Reinaldo Ayer de Oliveira (2008) Regional Council of Medicine of the State of São Paulo, Brazil.

18. Amaral CCG (2001) The avinguda family: gender in family relationships of adolescents. UFC, Fortaleza, Brazil.

19. Silva, Rudval SD, Amaral, Juliana BD, Malagutti W (2003) Organizers nursing in palliative care; caring for a good death. Martinari, São Paulo (SP), Brazil.
Creative Commons Attribution 4.0

International License

For possible submissions Click Here

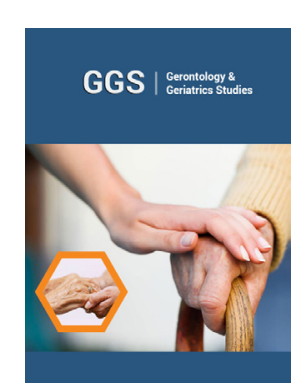

Gerontology \& Geriatrics Studies

Benefits of Publishing with us

- High-level peer review and editorial services

- Freely accessible online immediately upon publication

- Authors retain the copyright to their work

- Licensing it under a Creative Commons license

- Visibility through different online platforms 